\title{
De samenwerking tussen tandartsen en mondhygiënisten: van paradox naar oplossing
}

Het beroep van mondhygiënist is veranderd sinds de introductie van verticale taakherschikking. Deze verandering heeft echter nog niet geresulteerd in een optimale samenwerking tussen tandartsen en mondhygiënisten. Vier typische kenmerken van verticale taakherschikking worden als invloedrijke factoren beschouwd ten aanzien van samenwerking en acceptatie van verticale taakherschikking: de transitie van een hiërarchische werkrelatie naar een meer functionele werkrelatie, competentie en sociale status gerelateerd aan opleidingsniveau, de relatie tussen verticale taakherschikking en professionele identiteit en het ervaren nut van taakherschikking. Handvatten voor onderwijsontwikkeling worden gebaseerd op wetenschappelijke literatuur en geillustreerd met een voorbeeld uit het tandheelkunde curriculum van Groningen. Hoewel interprofessionele samenwerking op dit moment nog niet optimaal lijkt te zijn, bestaan er wel inzichten voor het versterken van de interprofessionele samenwerking tussen tandartsen en mondhygiënisten. Echter, meer aanknopingspunten zijn nodig. Vooral de paradox tussen professionele identiteit en interprofessionele samenwerking heeft nog weinig wetenschappelijke aandacht gekregen.

Reinders JJ, Blanksma NG. De samenwerking tussen tandartsen en mondhygiënisten: van paradox naar oplossing

Ned Tijdschr Tandheelkd 2012; 119: 317-322

doi: $10.5177 /$ ntvt.2012.06.12110

\section{Inleiding}

Het beroep van mondhygiënist is veranderd door de introductie van verticale taakherschikking waarbij tandartsen enkele tandheelkundige basistaken met mondhygiënisten delen (Schaub, 2008). Echter, deze verandering heeft nog niet bijgedragen aan een optimale samenwerking. Taakherschikking tussen tandartsen en mondhygiënisten stagneert en daarvoor bestaat geen eenduidige verklaring (Capaciteitsorgaan, 2010). De eigenlijke taakherschikking en het verschil in opleidingsniveau tussen tandartsen en mondhygiënisten leiden niet alleen tot juridische, praktische en organisatorische knelpunten maar resulteren ook in sociale en psychologische uitdagingen (Raad voor de Volksgezondheid en Zorg, 2002). Onduidelijk is welke sociaal-psychologische invloed de verticale taakherschikking heeft op de samenwerking. Vier invloedrijke kenmerken typeren de verandering in de samenwerking tussen tandartsen en mondhygiënisten: de transitie van een traditioneel hiërarchische naar een meer functionele werkrelatie, het verschil in opleidingsniveau tussen tandartsen en mondhygiënisten in relatie tot de wederzijds en subjectief waargenomen bekwaamheid, sociale status en de invloed van taakherschikking op de professionele identiteit. Daar- naast zal ook het ervaren nut van verticale taakherschikking invloed hebben op het succes van de verandering in de zorgverlening.

Bovengenoemde invloeden van verticale taakherschikking worden in dit artikel nader uitgewerkt om hun betekenis voor de samenwerking tussen tandartsen en mondhygiënisten te kunnen wegen. Voorts wordt het belang van de soort samenwerking voor het succes van verticale taakherschikking besproken. Tot slot zullen de praktische implicaties voor het onderwijs worden geillustreerd met een voorbeeld uit het Groningse curriculum.

\section{Transitie in werkrelatie}

De oorspronkelijke ondersteunende rol van de mondhygiënist is veranderd in de rol van een autonome beroepsbeoefenaar. In tegenstelling tot beroepen met een assisterende functie, wordt een 'autonoom beroep' gekenmerkt door een eigen expertisegebied, professionele autonomie, zelforganisatie en wettelijke erkenning (Adams, 2004). Het expertisegebied van de mondhygiënist is preventie, de mondhygiënist is vrij toegankelijk, heeft een eigen beroepsvereniging, wordt wettelijk erkend en heeft een beroepsopleiding die naar 4 jaar is uitgebreid. Deze ontwikkeling heeft de beroepsmatige verhouding met de tandarts veranderd omdat een autonoom beroepsbeoefenaar wezenlijk verschilt van een assistent of hulpkracht. De werkrelatie van een assistent of hulpkracht met een beroepsbeoefenaar is in principe een hiërarchische relatie omdat de assistent formeel niet autonoom is. Echter, de werkrelatie tussen 2 verschillende beroepsbeoefenaren is vooral functioneel. Het is de vraag in hoeverre de werkrelatie tussen tandartsen en mondhygiënisten daadwerkelijk meer functioneel is geworden. De samenwerking tussen tandartsen en mondhygiënisten is immers niet nieuw. Het beroep van mondhygiënist bestaat al sinds 1913 (Bagur, 1997). Lang genoeg voor het ontstaan van een samenwerkingscultuur met stabiele verhoudingen en sociale posities, verwachtingen en ingesleten routines. Verticale taakherschikking kan een werkrelatie dus wel formeel veranderen maar culturele veranderingen vergen doorgaans meer tijd. Mensen zijn geneigd om rollen te spelen die geassocieerd zijn met hun sociale positie. Dergelijke sociale posities onderscheiden zich van elkaar, hebben een bepaalde sociale status en duidelijk afgebakende verhoudingen met verwachtingen, waarden en normen. Wanneer in een sociaal systeem een rol verandert, zoals die van de mondhygiënist, komen traditionele verhoudingen met andere rollen, zoals hun werkverhouding met de tandarts, onder druk te staan (Parsons, 1970; Bennett, 2006). Ook de geslachtsverdeling binnen de tandheelkunde en de mondzorgkunde is bepa- 
lend voor de traditionele sociale verhoudingen. Geslacht beïnvloedt de hiërarchie binnen werkrelaties en geslachtsstereotypering is een zeer invloedrijke culturele variabele (Katz, 1996; Batalha, 2007). In Nederland wordt, evenals in de meeste andere landen, de tandheelkunde vooralsnog door mannen gedomineerd terwijl binnen de mondhygiëne voornamelijk vrouwen werkzaam zijn. Het aantal vrouwen binnen de tandheelkunde neemt echter snel toe, terwijl het aantal mannen binnen de mondhygiëne geleidelijk stijgt (Parkash et al, 2006).

\section{Verschil in opleidingsniveau, sociale status en de beroepsontwikkeling}

Naast de veranderingen binnen de samenwerkingscultuur waarin traditionele sociale verhoudingen verankerd liggen, kan ook het door beide beroepsgroepen waargenomen niveauverschil tussen hbo-opgeleide mondhygiënisten en academisch opgeleide tandartsen de professionele samenwerking beïnvloeden (Virtanen et al, 2011). Mondhygiënisten zijn bevoegd bepaalde tandheelkundetaken uit te voeren, al dan niet in opdracht van een tandarts. Het verschil in opleidingsniveau tussen tandartsen en mondhygienisten kan daarbij een knelpunt vormen (Headrick et al, 1998). Mondhygiënisten voeren immers taken uit die aanvankelijk exclusief onderdeel uitmaakten van het takenpakket van de hoger opgeleide tandarts. Hierdoor kunnen zowel bij tandartsen als mondhygiënisten twijfels ontstaan over bekwaamheid (Virtanen et al, 2011; Sprod en Boyles, 2003). Echter, wanneer beide beroepsgroepen ten aanzien van gedeelde taken exact dezelfde training ontvangen, zou het verschil tussen hbo en universiteit geen probleem hoeven te vormen.

Opleidingsniveau hangt samen met sociale status. Een taak kan een symbolische waarde hebben voor de beroepsgroep die zich met die taak vereenzelvigt. Taken worden geassocieerd met specifieke beroepen en daardoor ook met de sociale status van die beroepen (Omark, 1978). Het belang van sociale status wordt, naast andere factoren, beschreven door het Professional Project Model van Macdonald (1995) waarin het professionele ontwikkelingsproces centraal staat. Het model is ontwikkeld om te kunnen begrijpen hoe kennisintensieve beroepen die door de maatschappij als autonoom beroep geaccepteerd willen worden, te werk gaan om dit doel te bereiken. Het begint met de behoefte zich beroepsmatig van andere beroepsgroepen te willen onderscheiden. Vervolgens streeft men naar een hogere sociale status. Het is mogelijk dat mondhygiënisten mede daarom geneigd zijn hun takenpakket uit te willen uitbreiden met tandheelkundige taken (Adams, 2004). Niet omdat zij die specifieke taken nodig hebben om hun vak naar behoren uit te kunnen voeren en ook niet omdat het de uniekheid van het beroep bevordert. Een tandheelkundige taakuitbreiding zou de professionele status van de mondhygiënist kunnen verhogen. Hoewel de oorspronkelijke functie van verticale taakherschikking gerelateerd is aan het bevorderen van een integrale patiëntenzorg, schept dezelfde professionele hervorming kan- sen en uitdagingen die voor elke betrokken beroepsgroep kunnen verschillen.

\section{Professionele identiteit, interprofessionele samen- werking en taakherschikking}

Verticale taakherschikking verandert het 'professionele landschap'. Taakherschikking zorgt ervoor dat bepaalde taken niet langer exclusief zijn. Als beroepsbeoefenaren vinden dat bepaalde taken de uniekheid van hun beroep definiëren en deze taken vervolgens met een andere beroepsgroep gedeeld worden, beïnvloedt dit ongetwijfeld de samenwerking tussen die beroepsgroepen.

In elk mens schuilt een soort 'cartograaf' die de wereld en zijn eigen positie daarin in kaart brengt. Die wereld wordt beschreven in termen van mentale representaties waarvan de professionele identiteit een onderdeel is (Fodor, 1985). De mens ontdekt die identiteit niet, zij construeert haar zelf (Bauman, 2004). Professionele identiteit is daarmee een zelfgeconstrueerde mentale representatie van onze professionele rol in een sociale omgeving. Wanneer onze omgeving die professionele rol door taakherschikking wijzigt, dient ook de eigen mentale representatie van de professionele rol te veranderen, net als het bijpassende takenpakket. Echter, het veranderen van een professionele identiteit wordt meestal als een bedreiging ervaren en roept dus weerstand op (Hean et al, 2006).

In het geval van taakherschikking gebeurt waarschijnlijk hetzelfde. De grenzen tussen het beroep van de tandarts en dat van de mondhygiënist lijken te vervagen. De 2 beroepsgroepen gaan meer op elkaar lijken en zo kan het gevoel ontstaan dat de identiteit van beide beroepsgroepen wordt bedreigd (Headrick et al, 1998). Onderscheid te kunnen maken tussen de eigen beroepsgroep en andere beroepsgroepen is dus van groot belang. Een professionele identiteit is een sociale identiteit waarbij een individuele beroepsbeoefenaar de behoefte heeft zichzelf als groepslid te onderscheiden van andere beroepsgroepen ('psychological distinctiveness') (Tajfel en Turner, 1979). Taakherschikking lijkt het tegengestelde te doen: tandartsen en mondhygiënisten gaan meer op elkaar lijken doordat zij overeenkomstige taken delen. Taakoverlapping is tevens 1 van de essentiële kenmerken van interprofessionele samenwerking (Lindeke en Block, 1998). Deze paradox draagt zeer waarschijnlijk bij aan de stagnatie van de taakherschikking tussen tandartsen en mondhygiënisten. De paradox waarbij professionele identiteit en interprofessionele samenwerking elkaars schijnbare tegenpolen zijn, werd al eerder onderkend door Whittington (2003). Tandartsen staan minder positief tegenover taakherschikking dan mondhygiënisten en mondhygiënisten staan positiever tegenover professionele autonomie dan tegenover taakherschikking (Adams, 2004; Reinders et al, 2012b). Hoewel beide beroepsgroepen tegengestelde belangen lijken te ervaren, kan dit dus een aanwijzing zijn dat zij wel hetzelfde willen: een eigen beroep dat zich van andere beroepen kan onderscheiden en volwaardig en dus autonoom is. Dit zou de waargenomen tegenstelling tussen de 
beroepsgroepen dan inderdaad tot een schijnbare tegenstelling maken. Echter, om dit laatste te kunnen bewijzen is meer onderzoek nodig.

\section{Het nut van taakherschikking}

Alvorens taakherschikking in te voeren, is het van belang te weten welke meerwaarde die kan hebben voor de zorgverlening en voor de betrokken beroepsgroepen. Wereldwijd is er veel positieve belangstelling voor interprofessionele samenwerking (Strasser et al, 2005). Hoewel samenwerking tussen beroepsgroepen van zorgverleners tegenwoordig een vertrouwd concept is, ligt de oorsprong ervan in het collectieve partnerschap binnen overheidsinstanties en de privésector (Mitchell en Crittenden, 2000). In de jaren '70 van de vorige eeuw werd interprofessionele samenwerking in de zorg voor het eerst geformaliseerd in de vorm van teams die individuele en persoonlijke zorg verleenden. Het concept kreeg eind jaren '80 opnieuw aandacht vanwege aanwijzingen dat door deze vorm van samenwerken levens werden gered. Binnen de huidige gezondheidszorg vinden nog steeds veel veranderingen plaats met als doel het optimaliseren van de organisatie van de zorg op verschillende niveaus. Samenwerkende beroepsgroepen leveren met betrekking tot alle aspecten van de patiëntenzorg hun bijdrage vanuit een breder perspectief (Baldwin, 2000). Het hervormen van zorgrollen, en daarmee van de bestaande samenwerkingsrelaties, leidt op operationeel niveau tot nieuwe werkwijzen (Knip, 2006). Geen enkele individuele discipline of beroepsgroep is meer in staat de volledige zorg van een patiënt alleen op zich te nemen (Xyrichis en Lowton, 2008). Daarnaast is gebleken dat vergaande professionele specialisatie heeft geleid tot fragmentatie tussen verschillende beroepen waardoor het praktisch onmogelijk wordt om problemen op een holistische manier te benaderen (Buchan et al, 2001). Wanneer problemen elkaar overlappen of in elkaars verlengde liggen, is een goede organisatie van teamwork vereist (Hall en Weaver, 2001). Die organisatie verloopt, om meerdere redenen, niet altijd vlekkeloos. Problemen behoren soms tot verschillende disciplinegebieden en wanneer problemen met elkaar interfereren, is de beste oplossing voor het ene probleem niet altijd de beste oplossing voor een ander probleem van dezelfde patiënt. Het kan zelfs gebeuren dat een oplossing van een specifieke discipline het probleem vergroot dat door een andere discipline is waargenomen (Stoffels, 2008). Gebrek aan samenwerking kan leiden tot negatieve uitkomsten, zoals dubbel werk, vertragingen en fouten (Øvretveit et al, 1997).

Binnen de mondzorg is in verschillende landen een tekort aan tandartsen vastgesteld (Raad voor de Volksgezondheid en Zorg, 2002; Marshall en Spencer, 2006). Het huidige zorgaanbod blijft achter bij de stijgende vraag naar mondzorg. Het aantal gezondheidsproblemen per individuele patiënt neemt toe door de vergrijzing. Verbetering van effectieve zorg door integrale benadering vergt goede interprofessionele samenwerking.

Met drastisch stijgende kosten is kostenreductie een ander belangrijk motief voor het stimuleren van interprofessionele samenwerking in de zorg. Ook het verbeteren van het management van organisaties en individuele medewerkers, het handhaven van de zorgkwaliteit, technologische innovatie en veranderingen in wet- en regelgeving kunnen ten grondslag liggen aan de behoefte en noodzaak tot meer samenwerking tussen beroepsgroepen (Buchan et al, 2001)

Om de stagnatie van taakherschikking tussen tandartsen en mondhygiënisten te kunnen oplossen, is het nodig na te gaan waarin verschillende professionele samenwerkingsvormen van elkaar verschillen. Vervolgens is het van belang na te gaan welke samenwerkingsvorm tussen tandartsen en mondhygiënisten het meest gangbaar is en hoe dit gerelateerd kan worden aan verticale taakherschikking.

\section{Verschillende samenwerkingsvormen}

Verschillende vormen van professionele samenwerking zijn te plaatsen op een continuüm van uniprofessioneel naar transprofessioneel (Headrick et al, 1998). Er is sprake van uniprofessionele samenwerking wanneer het een samenwerking tussen de leden van dezelfde beroepsgroep betreft. Een andere vorm is de multiprofessionele samenwerking, waarbij een expliciete scheiding van taken bestaat tussen 2 of meer beroepsgroepen. De samenwerking is dan alleen gericht op coördinatie. Bij interprofessionele samenwerking bestaat er een overlap in het takenpakket van 2 of meer beroepen. Dit laatste is bij taakherschikking het geval. Bovendien kenmerkt interprofessionele samenwerking zich door inhoudelijke afstemming tussen 2 of meer beroepen. Verschillende beroepsgroepen delen de besluitvorming en zijn samen verantwoordelijk voor de zorgplanning. Een professionele samenwerking waarbij 2 of meer beroepsgroepen exact dezelfde taken uitvoeren, wordt transprofessionele samenwerking genoemd.

Hoewel in de wetenschappelijke literatuur steeds vaker onderscheid wordt gemaakt tussen de verschillende vormen van professionele samenwerking op basis van het aantal betrokken beroepsgroepen ( 2 of meer) en het type interactie daartussen, worden termen als multiprofessionaliteit en interprofessionaliteit nog vaak als uitwisselbare concepten toegepast (Headrick et al, 1998). Dit kan tot onnodige verwarring leiden omdat juist het type interactie tussen beide beroepsgroepen van belang is voor het begrijpen van de stagnatie van taakherschikking tussen tandartsen en mondhygiënisten vanuit een organisatiepsychologisch perspectief.

Als de formele definitie wordt gehanteerd, is de samenwerking tussen tandartsen en mondhygiënisten niet te typeren als een multiprofessionele samenwerking. Multiprofessionaliteit kenmerkt zich tenslotte door een strikte scheiding tussen de taken van 2 of meer beroepsgroepen. Verticale taakherschikking tussen tandartsen en mondhygiënisten leidt juist tot een taakoverlapping. De samenwerking tussen de beroepsgroepen zou dan interprofessioneel moeten zijn. Interprofessionaliteit kenmerkt zich echter niet alleen door een taakoverlapping maar omvat ook een 
gedeelde besluitvorming en zorgplanning. Alleen wanneer beide beroepsgroepen autonoom zijn, is interprofessionele besluitvorming mogelijk. Wet- en regelgeving kunnen die gelijkwaardige besluitvorming vastleggen, maar het zijn de mensen in het werkveld die veranderingen daadwerkelijk mogelijk maken (Johnson, 2009). Verschillende onderzoeken laten niettemin zien dat de autonomie van mondhygiënisten nog niet tot volle wasdom is gekomen (Adams, 2004; Kravitz en Treasure, 2007). Het feit dat voor het uitvoeren van een aantal verrichtingen de opdracht van een tandarts is vereist, is hieraan mede debet.

De vraag is of een mondhygiënist onder die voorwaarden een assistent of hulpkracht met een taakuitbreiding is of een beroepsbeoefenaar met (secundaire) tandheelkundige basistaken. De traditionele verhouding van de mondhygiënist met de tandarts is een ondersteunende werkrelatie. Het opleidingsverschil tussen tandartsen en mondhygiënisten en de geslachtsverdeling binnen de beroepsgroepen zou die traditionele verhouding in stand kunnen houden. Bovendien wordt de taakherschikking tussen tandartsen en mondhygiënisten 'verticaal' genoemd en heeft de term 'verticale taakherschikking' een hiërarchische connotatie. Wanneer interprofessionele samenwerking bevorderd dient te worden, moet worden nagegaan welke factoren bijdragen aan het succes van een dergelijke samenwerking.

\section{Het Groningse regiemodel}

De uitdagingen rond interprofessionele samenwerking tussen tandartsen en mondhygiënisten hebben tot het Groningse regiemodel geleid. Hierbij fungeert de tandarts als regisseur van de mondzorg (Stegenga et al, 2010). Naast mondhygiënisten worden ook andere spelers door de tandarts geregisseerd, zoals preventieassistenten, gedifferentieerde en gespecialiseerde tandartsen. Dit betekent dat de tandarts het overzicht dient te bewaren op het integrale zorgtraject van individuele patiënten en op de samenwerking tussen alle actoren. Dit artikel beperkt zich tot de samenwerking tussen tandartsen en mondhygiënisten terwijl de regierol van de tandarts eigenlijk breder is.

Wanneer tandartsen en mondhygiënisten goed zicht hebben op elkaars takenpakket, professionele grenzen en interprofessionele raakvlakken kan integrale zorg tot stand komen. Voor de integrale totstandkoming van een individueel behandelplan is tussen tandartsen en mondhygiënisten overleg nodig dat niet zozeer een informerend en delegerend karakter heeft, maar dat vooral een inhoudelijke en planmatige afstemming betreft. Zowel tandartsen als mondhygiënisten zouden deze wijze van samenwerken a tijdens hun opleiding moeten leren. In dergelijk overleg moeten beide (toekomstige) zorgverleners de patiëntcasuistiek geïntegreerd kunnen benaderen. Met andere woorden: zij moeten samen kunnen nagaan hoe de expertise van beide beroepen elkaar kunnen versterken in het nastreven van optimale zorg. Het gaat dan niet langer om gescheiden kennisdomeinen (zoals bij multiprofessionele samenwerking het geval is) maar om onderling afhankelijke kennisdomeinen die elkaar aanvullen. Voor de mond- zorg betekent dit dat tandartsen en mondhygiënisten ieder de samenhangende klinische voorwaarden scheppen die nodig zijn voor het behalen van een optimaal resultaat in het voordeel van de patiënt.

De Groningse opleidingen Tandheelkunde (Rijksuniversiteit Groningen/Universitair Medisch Centrum Groningen) en Mondzorgkunde (Hanzehogeschool Groningen) hanteren 3 vormen van professioneel onderwijs: uniprofessioneel, multiprofessioneel en interprofessioneel. Het inzicht dat professionele identiteit en interprofessionele samenwerking elkaars schijnbare tegengestelden zijn, heeft geleid tot nieuwe ontwikkelingen binnen het onderwijs van beide opleidingen. Tandheelkunde heeft meer interprofessioneel onderwijs geïntroduceerd omdat dit type onderwijs zich expliciet richt op professionele kennismaking en socialisatie (Lee en Williams, 1994). Wanneer studenten beter op de hoogte zijn van elkaars (toekomstige) takenpakket en de grenzen van dat pakket, zijn ze beter in staat in te schatten hoe zij elkaar beroepsmatig kunnen aanvullen. Daarnaast dienen studenten zich bewust te zijn van de principes en mogelijkheden rond interprofessionele samenwerking. Dit bewustzijn kan samenwerkingsstijlen gerelateerd aan traditionele verhoudingen veranderen en interprofessionele samenwerking stimuleren (Morison et al, 2008). Omdat studenten tandheelkunde en mondzorgkunde een andere wettelijke status bezitten dan afgestudeerde (en geregistreerde) tandartsen en mondhygiënisten, dient het onderwijs dat verschil in bevoegdheden te ondervangen. Dat kan gebeuren door gebruik te maken van samenwerkingssimulaties en studenten onderdeel te laten zijn van klinische besluitvorming die is ingebed in een supervisiemodel met bevoegde klinische docenten.

Een voorbeeld van een Groningse samenwerkingssimulatie is de 'Oral Health Practice Game'. Deze simulatie is in 2011 ingevoerd. Aan de simulatie gaat een onderwijsreeks vooraf waarbij verschillende zorgverleners de studenten gezamenlijk theoretisch voorbereiden op onder andere wetgeving, teamontwikkeling en bedrijfsorganisatie in relatie tot interprofessionele samenwerking. De praktische onderwijsreeks betreft de 'Oral Health Practice Game'. Gemengde teams van 4 tot 6 studenten tandheelkunde en mondzorgkunde krijgen vervolgens de opdracht om een interprofessionele mondzorgpraktijk op te zetten. Via intranet krijgt ieder team toegang tot opdrachten die te maken hebben met de bedrijfskundige opzet van hun fictieve mondzorgpraktijk. Daarnaast moeten de studenten de juridische kaders voor samenwerking, de praktijkorganisatie, de klinisch inhoudelijke afstemming en de teambuilding voor hun gesimuleerde praktijk uitwerken. De interprofessionaliteit van elk team wordt in een voorronde beoordeeld. Tot slot gaan de 4 beste teams door naar de finale van de Integralis Competitie en ontvangt het winnende team de prijs voor de meest interprofessionele mondzorgpraktijk: de Integralis Prijs. Door competitie tussen interprofessionele groepen te stimuleren, wordt op een positieve manier gebruik gemaakt van de menselijke neiging om de eigen groep voor te trekken en een positievere 
houding jegens eigen groepsleden te ontwikkelen in vergelijking met andere groepen. Hierdoor kan niet alleen een positieve houding worden gestimuleerd ten opzichte van interprofessionaliteit maar wordt ook getracht het ontstaan van competitie tussen beide beroepsgroepen tegen te gaan. Dergelijke competitie kan immers, door hetzelfde mechanisme, tot meer sociale afstand leiden. Dit mechanisme, beter bekend als het 'ingroup-outgroup mechanisme', is gebaseerd op de 'Social Identity Theory' van Tajfel en Turner (1979).

In 2011 is de 'Oral Health Practice Game' geëvalueerd door 53 studenten naar hun mening te vragen met betrekking tot de waargenomen samenwerking en professionele identiteit in relatie tot het ervaren imago. Het onderzoek had een respons van $79 \%$. Van de respondenten vond 51\% dat de simulatie hen hielp zich in te leven in de professionele rol. De professionele context van de simulatie zou daarom versterkt dienen te worden. Deze 51\% van de studenten vond hun eigen team doorgaans interprofessioneler dan andere teams. Van de respondenten vond $76 \%$ dat hun eigen team ten minste op nominaal niveau functioneerde. Met nominaal teamniveau wordt bedoeld dat een team een sociale samenhang heeft (zonder subgroepen of geïsoleerde teamleden) en productief genoeg is om de opdrachten binnen de vastgestelde tijd uit te werken. Meerdere deelnemers gaven echter aan dat er meer tijd beschikbaar zou moeten zijn om een betere teamontwikkeling mogelijk te maken en de opdrachten diepgaander uit te kunnen werken. Van alle respondenten vond $60 \%$ dat zij daadwerkelijk interprofessioneel hebben samengewerkt.

Tot slot werd de ervaren sociale interactie tijdens de simulatie gemeten door studenten tandheelkunde en mondzorgkunde te vragen welke eigenschappen zij zichzelf en elkaar toekennen. Deze meting was gebaseerd op het Claim-Affirmation Model van Holmes (2001) waarbij een persoon aanspraak kan maken op bepaalde kenmerken of deze kenmerken juist verwerpt. Daarnaast kan een persoon het gevoel hebben dat diezelfde kenmerken worden bevestigd of juist worden verworpen door zijn sociale omgeving, in dit geval de samenwerkingspartners. Professionele kenmerken waren vooraf geïnventariseerd met semigestructureerde interviews en waren verder afkomstig uit een literatuuronderzoek naar samenwerking. Verschillende niveau-, bekwaamheids-, communicatieve en relationele kenmerken werden door de studenten beoordeeld met een psychometrische 6-puntenschaal met tegenovergestelde begrippen op de 2 uitersten.

Uit de resultaten bleek dat $96,4 \%$ tot $100 \%$ van de studenten tandheelkunde overeenstemming had ervaren tussen hun professionele identiteit en hun professioneel imago onder studenten mondzorgkunde. Zij kregen het gevoel dat studenten mondzorgkunde hen slimme, bekwame en hoog intelligente beroepsbeoefenaars vonden en maakten ook zelf aanspraak op die kenmerken. Van alle studenten tandheelkunde kreeg $21,4 \%$ tot 33,3\% het gevoel dat identiteit en imago niet met elkaar in overeenstemming waren. Studenten mondzorgkunde gaven hen het gevoel dat zij solistisch, tegenwerkend en conservatief waren. Van alle studenten mondzorgkunde vond 96\% zichzelf sympathiek, vriendelijk en meewerkend. Studenten tandheelkunde gaven hen ook het gevoel dat zij over die $3 \mathrm{ei}^{-}$ genschappen beschikten. Echter, 20,8\% tot 28\% van alle studenten mondzorgkunde kreeg het gevoel dat studenten tandheelkunde hen een laag niveau, onderdanigheid en volgzaamheid toekenden.

De eerste resultaten van de Oral Health Practice Game zijn veelbelovend, maar er is ruimte voor verbetering. Op basis van de resultaten worden daarom direct nieuwe verbeteringen doorgevoerd die op hun beurt geëvalueerd zullen worden. De samenwerking tussen tandartsen en mondhygiënisten zal in Groningen, ook in de toekomst, een speerpunt blijven.

\section{Tot slot}

In de beschreven literatuur en onderwijservaringen zijn aanwijzingen te vinden dat de samenwerking tussen tandartsen en mondhygiënisten niet alleen verbeterd moet worden maar ook kan worden. De profilering van beroepsverenigingen en opleidingen kunnen traditionele verhoudingen veranderen, opleidingen kunnen interprofessionaliteit versterken door interprofessioneel onderwijs aan te bieden en de professionele identiteit van haar studenten te beïnvloeden door zelf een interprofessionele voorbeeldrol te spelen. Ook wanneer zorgverleners uit het werkveld zich meer bewust worden van de verschillende vormen van professionele samenwerking en van het nut van de interprofessionele samenwerking in het bijzonder, kan de kwaliteit van de mondzorg door een meer integrale samenwerking worden vergroot. Wederzijdse behoeften en belangen van tandartsen en mondhygiënisten moeten dan wel worden herkend en erkend. Voorts moeten de sociaalpsychologische implicaties van interprofessionele samenwerking, in het bijzonder taakherschikking, niet worden onderschat. Meer wetenschappelijk onderzoek kan een bijdrage leveren aan het oplossen van de paradox tussen professionele identiteit en interprofessionele samenwerking. Het belang van de patiënt dient immers de belangen van afzonderlijke beroepsgroepen te overstijgen.

\footnotetext{
Literatuur

* Adams TL. Inter-professional conflict and professionalization: dentistry and dental hygiene in Ontario. Soc Sci Med 2004; 58: 2243-2252. * Bagur DB. The dental assistant in Argentina. Rev Museo Fac Odontol B Aires 1997; 12: 17-25.

* Baldwin DC. Health care teamwork. Westport: Auburn House, 2000.

* Batalha L, Akrami N, Ekehammar B. Outgroup favoritism: the role of power perception, gender, and conservatism. Curr Res Soc Psychol 2007; 13: 39-49.

* Bauman Z. Identity: Conversations with Benedetto Vecchi. Cambridge: Polity, 2004

* Bennett ML. The rural family nurse practitioner: the quest for roleidentity. J Adv Nurs 2006; 9: 145-155.

* Buchan J, Ball J, O'May F. If changing skill mix is the answer, what is the question? J Health Serv Res Policy 2001; 6: 235-236.
} 
* Capaciteitsorgaan. Capaciteitsplan 2010. Voor de medische, tandheelkundige, klinisch technologische en aanverwante (vervolg)opleidingen. Utrecht: Stichting Capaciteitsorgaan voor Medische en Tandheelkundige Vervolgopleidingen, 2010

* Fodor JA. fodor's guide to mental representations. Mind 1985; 94 : 76 100.

* Hall P, Weaver L. Interdisciplinary education and teamwork: a long and winding road. Med Educ 2001; 35: 867-875

* Headrick LA, Wilcock M, Batalden B. Interprofessional working and continuing medical education. BMJ 1998; 316: 771-774.

* Hean S, Macleod CJ, Adams K, Humphris D, Lathlean J. Being seen by others as we see ourselves: the congruence between the ingroup and outgroup perceptions of health and social care students. Learn Health Soc Care 2006; 5: 10-22.

* Holmes L. Reconsidering graduate employability: the graduate identity approach. Quality in Higher Education 2001; 7: 111-120.

* Johnson PM. International profiles of dental hygiëne 1987 to 2006: a 21-nation comparative study. Int Dental J 2009; 59: 63-77.

* Katz PA. Raising feminists. Psychol Women Quarterly 1996; 20 : 323-340.

* Knip M. Werken met nurse practitioners: effecten van functiedifferentiatie op de grens van care en cure. Assen: Van Gorcum, 2006.

* Kravitz AS, Treasure ET. Utilisation of dental auxiliaries - attitudinal review from six developed countries. Int Dent J 2007; 57: 267-273.

* Lee DB, Williams PT. Prospective management and longitudinal care: The dynamic changing nature of team activity. In: Castro RM, Julia MC (eds.). Interprofessional care and collaborative practice. Belmont: Brooks/Cole, 1994

* Lindeke LL, Block DE. Maintaining professional integrity in the midst of interdisciplinary collaboration. Nurs Outlook 1998; 46: 213-218.

* Macdonald K. The sociology of the professions. Thousand Oaks: Sage, 1995.

* Marshall RI, Spencer AJ. Accessing oral health care in Australia. Why try a doctor when you need a dentist? MJA 2006; 185: 59-60.

* Mitchell PH, Crittenden RA. Interdisciplinary collaboration: old ideas with new urgency. Wash Public Health 2000;17; 51-53.

* Morison S, MarleyJ, Stevenson M, Milner S. Preparing for the dental team: investigating the views of dental and dental care professional students. Eur J Dent Educ 2008; 12: 23-28.

* Omark RC. Training therapy of psychotherapists: professional socialization as interprofessional relations. Psychol Rep 1978; 42: 13071310.

* Øvretveit J, Mathias P, Thompson T. Interprofessional working for health and social care. Basingstoke: Macmillan, 1997.

* Parkash H, Mathur VP, Duggal R, Jhuraney B. Dental workforce issues: a global concern. J Dent Educ 2006; 70: 22-26.

* Parsons T. The Social System. Londen: Routledge \& Kegan Paul Ltd., 1970.

* Reinders JJ, Onclin P, Schans CP van der, Stegenga B. How attitudes of dentists and dental hygienists towards task redistribution are related to gender: a review. Int J Psychol (Special Issue); 2012b: in druk.

* Raad voor de Volksgezondheid en Zorg. Taakherschikking in de gezondheidszorg, Zoetermeer: Raad voor de Volksgezondheid en Zorg aan de minister van Volksgezondheid, Welzijn en Sport, 2002.

* Schaub R. Samenwerken in de mondzorg. Houten: Bohn Stafleu van Loghum, 2008.

* Sprod A, Boyles J. The workforce of professionals complementary to dentistry in the general dental services: a survey of general dental practices in the South West. Br Dent J 2003; 194: 389-397.

* Stegenga B, Cune MS, Tams J. De bakens verzetten - regie en topklinische zorg. Profiel van de Groningse opleiding tot tandarts als basis voor organisatieverandering CTM. Interne notitie. Groningen: Universitair Medisch Centrum Groningen/Centrum voor Tandheelkunde en Mondzorgkunde, 2010.

* Stoffels AMR. Cooperation among medical specialists: 'Pain' or 'gain'. Dissertatie. Groningen: Rijksuniversiteit Groningen/Faculteit Bedrijfskunde, 2008.

* Strasser DC, Falconer JA, Herrin JS, Bowen SE, Stevens AB, Uomoto J. Team functioning and patient outcomes in stroke rehabilitation. Arch Phys Med Rehabil 2005; 86: 403-409.

* Tajfel H, Turner JC. Social comparison and group interest in ingroup favouritism. Eur J Soc Psychol. 1979; 9: 187-204.

* Virtanen JI, Tseveenjav B, Wang NJ, Widström E. Nordic dental hygienists' willingness to perform new treatment measures: barriers and facilitators they encounter. Scand J Caring Sci. 2011; 25 311-316.

* Whittington, C. A model of collaboration. In: Weinstein J, Whittington C, Leiba T (eds.). Collaboration in Social Work Practice. Londen: Jessica Kingsley, 2003.

* Xyrichis A, Lowton $K$. What fosters or prevents interprofessional teamworking in primary and community care? A literature review. Int J Nurs Stud 2008; 45, 140-153.

Summary

\section{The collaboration between dentists and dental hygienists: from paradox to resolution}

The occupation of dental hygienist has changed since the introduction of vertical task redistribution. However, this change has not yet resulted in an optimal collaboration between dentists and dental hygienists. Four typical characteristics of vertical task redistribution are considered to be influential factors with respect to collaboration and the acceptance of vertical task redistribution: the transition from a hierarchical work relation to a more functional work relation, educational level as related to competence and social status, the relation between vertical task redistribution and professional identity and the perceived usefulness of interprofessional collaboration and task redistribution. Implications for educational development are based on scientific literature and are illustrated by an example from the dental curriculum in the Dutch city of Groningen. Even though interprofessional collaboration does not seem to be optimal at the present time, there are insights that suggest ways of improving interprofessional collaboration between dentists and dental hygienists. However, more clues are needed. In particular, the paradox between professional identity and interprofessional collaboration has not yet received much scientific attention.

\section{Bron}

J.J. Reinders ${ }^{1}$, N.G. Blanksma²

Uit ${ }^{1}$ de vakgroep Mondgezondheidszorg en Klinische Epidemiologie en ${ }^{2}$ de vakgroep Conserverende tandheelkunde van het Centrum voor Tandheelkunde en Mondzorgkunde van het Universitair Medisch Centrum Groningen

Datum van acceptatie: 26 maart 2012

Adres: J.J. Reinders, UMCG, postbus 196, 9700 AD Groningen

j.j.reinders@umcg.nl 